\title{
Choosing between Alternative Motor Insurance Policies: A Discrete Choice Experiment
}

\author{
Charles Kwofie (D), Dieu Donne Yormekpe $\mathbb{D}$, Samuel Osei Mensah, and Priscilla Botchway \\ University of Energy and Natural Resources, Department of Mathematics and Statistics, Ghana \\ Correspondence should be addressed to Charles Kwofie; charles.kwofie@uenr.edu.gh
}

Received 13 June 2018; Revised 12 August 2018; Accepted 30 August 2018; Published 26 September 2018

Academic Editor: Frank Werner

Copyright (c) 2018 Charles Kwofie et al. This is an open access article distributed under the Creative Commons Attribution License, which permits unrestricted use, distribution, and reproduction in any medium, provided the original work is properly cited.

\begin{abstract}
The research expounds the use of Discrete Choice Experiment (DCE) approach and Random Utility Theory (RUT) in analyzing alternative motor insurance policy choice behaviour for drivers in Sunyani municipality in Brong-Ahafo, Ghana. We design a DCE to identify the factors (premium cost, claims settlement, customer satisfaction, and proximity) that influences an individual choice for insuring with a particular insurance company given the existence of an alternative. Probit model was used in estimating the parameters of the consideration sets of the DCE. The research sampled 100 respondents comprising mainly of private and commercial drivers. The magnitude of estimates from both probit model and estimated marginal effects indicates respondents highly value insurers with the attribute of paying claims promptly, charging moderate premium, and closer in terms of proximity. However, customer satisfaction will result in a disutility of choice of insurer. Also, the levels of customer satisfaction can be traded off for other attributes.
\end{abstract}

\section{Introduction}

Security is widely sought after by individuals. After food, clothing, and shelter a sense of security is the subsequent basic goal. Anderson \& Brown [1] asserted that an individual is somewhat certain in satisfying his needs (food, shelter, medical care, etc.) in the present and near future if he has economic security of which insurance can play a role. Insurance has over the period been noted as one of the components of the nonfinancial industry that have consistently found their way in the lives of individuals more especially in the sub-Saharan region. Insurance as a whole is more than just compensating losses [2] but also has an incentive to control them which is significantly a social benefit [3]. According to Insurance Australia Group [4], insurance is a way of decreasing adversities and reassigning risks so as to shield impending major expenses due to death, sickness, robbery, or accident. According to Onafalujo \& Kunle [5], the creation of the vehicle brought forth the need to protect motorists from the possibly huge financial loss from operating a car. Road transportation has embedded morbidity and mortality risks in most countries since it is the most common means of commutation [6]. Road transportation is one main mechanism of commuting in Ghana. Most people in the country depend on road transport for their daily commutation, as well as the delivery of raw materials and food commodities. To be able to manage the risks posed by the road transport industry, motor insurance is key as it also serves as the means to improve upon the damages arising from accidents and other catastrophes. Motor insurance is by far a compulsory nonlife insurance among transport, property, personal accident, and general liability insurance in Ghana. With obligatory insurance in place, monetary threats rising from the use of vehicles can be well taken care of. As a result of this, motor vehicle insurance has advanced into a significant method of contract arising out of or in relation to the use of vehicles and third parties inclusively. Third-party motor insurance is compulsory in majority of countries worldwide, which is a true revelation of modern-day developments in acquiring reimbursement of traffic accident victims. As a result, the working of this policy is of high significance to many people [7]. According to Rossi et al., [8], theories on the demand for insurance have been built on anticipated utility in economics and guaranteed preference for definite issues over indefinite ones of the same degree. The decision to buy insurance not only depends on the apparent current situation of the product or service but 
depends also on its future conditions and this constitutes the demand for insurance [9]. Beenstock et al. [10] opined that an individual extends their economic range of preference and chance by guarding themselves from financial losses in a case of an accident, fire, or theft. As a result insurance pricing is a very important component in the determination of the demand for insurance [11]. Browne et al. [12] noted that an individual's income and wealth, the fee of insurance, the likelihood of damage, and individual degree of aversion of risk influence the request for insurance coverage. Gujarati [13] studied the demand for insurance by bearing in mind three different variables which are variables encouraging demand as a result of the efforts of the insurer, variables affecting household saving choice, and variables determining the ability to pay which is similar to the concept of no premium no cover in the Ghanaian insurance industry. It was revealed in their study that the demand for insurance is affected positively by the changes in the income and wealth status of the consumer. In this study, the authors through indepth interviews with experts in the insurance industry were able to identify four pressing factors that affect the demand for motor insurance in Ghana. The factors are premium cost, claims settlement, customer satisfaction, and proximity of the company. Theoretically there are numerous models to enhance effective choice making. Damaraju et al. [14] saw that, in actual life situations, customers disclose their favorites by making choices and that the collection of selections makes up the demand for merchandises and services and many other phenomena of interest. Day in day out individuals are faced with a great difficulty in the selection of the required policy from an insurance provider and on the other hand insurers also face the daunting task of identifying the key factors to employ in order to gravitate these individuals to come work with them. In a wider context, we seek to identify the main factors that influence individuals' choice of motor insurance policy from a particular insurer and use a Discrete Choice Experiment (DCE) and Discrete Choice Modeling (DCM) which is embedded in Random Utility Theory (RUT) to estimate the effect of these factors.

\section{Materials and Methods}

2.1. Sampling and Data Gathering Process. The study used simple random sampling technique. It targeted vehicle drivers in the Sunyani municipality since the research sought to examine the hypothetical selection of an insurance company by these individuals. 100 respondents making up the sample size were selected for the study. With an entire sample of fifty (50) people, with each presented with at least 16 choice groups and completely generic parameter description for design characteristics and covariates might be sufficient for choice research [15].

\subsection{Revealed and Stated Preference Surveys}

2.2.1. Small Revealed Preference. Revealed preference data complements stated preference data. It relates to the choices individuals make in actual life conditions. They are as such because individuals disclose their tastes or preferences through day to day choices they make in the world. In the RP method actual behaviour is observed, rather than presenting the respondent with a hypothetical situation.

\subsubsection{Advantages and Shortcomings}

(1) Revealed preference data reflects on actual choices in real life settings.

(2) Such data are restricted to the choice circumstances and attributes of alternatives that exist currently or have historically existed.

(3) Revealed preference data are simply not useful in situations that do not currently exist.

2.2.3. Stated Preference. Stated Preference data are collected through experimental settings or a survey whereby respondents are presented with imaginary choice problems. SP approaches are a collection of techniques which utilize statements got from respondents around their preferences in a set of choices to evaluate their utility functions.

\subsubsection{Advantages and Shortcomings}

(1) The benefit of stated preference survey data is that the researcher designs the experiments as he or she thinks is appropriate to comprise of as much variation in each attribute as possible.

(2) For each respondent, attributes can be varied over experiments and over respondents.

(3) The restrictions of stated preference data are clear: what people in reality say they will do is not the same as what they really do often; i.e., individuals might not have the slightest idea of what they would do if a hypothetical situation was actually real.

Widely, stated choice trial has been used in choice settings in life. Individuals were asked to make a choice amid hypothetical insurance companies from a dual choice set in this study. This method necessitates individuals to substitute the diverse characteristics of insurance company attributes in a choice task. SP approach rises the number of responses and also offers the opportunity of trade-offs between the choices available, as with each trade-off the individual specifies his/her favorite. The substitutes in the choice set however were wellthought-out to be the most pressing factors influencing motor insurance policy purchase in the Sunyani municipality.

2.3. Determination of Attributes and Levels. Four motor insurance company attributes and corresponding levels were identified by the author to be the most important. The initial list of probable attributes was obtained through interviews with individuals and some local experts. In designing a SP survey, it is suggested that attribute levels should be genuine and possess the capability of being traded. According to Adamowvic et al. [16] attributes are often obtained from primary or secondary investigation or prior experience. However discussions were held among focus group to decrease 
TABLE 1: Attributes and corresponding levels.

\begin{tabular}{lc}
\hline Attributes & Corresponding Levels \\
\hline Premium Cost & Maximum, Moderate, and Minimum \\
\hline Claims Settlement & Prompt, Delayed \\
\hline Customer Service & Good, Satisfactory \\
\hline Proximity & Near, Far \\
\hline
\end{tabular}

the prior list of possible attributes to four (i.e., premium cost, claims settlement, customer satisfaction, and proximity). The company choice attributes with their respective levels are defined in Table 1.

2.4. Experimental Design. The experimental design process being the next stage in DCEs aids in simulating choice sets to be offered to the respondents. Experimental design aids in organizing and running our experiment. According to Louviere et al., [17], it is a means of controlling attributes and their levels to enable rough analysis of some hypothesis of concern. The DCE questionnaires choice sets were produced using firm statistical procedures. DCE macros embedded in the statistical programme SPSS were used in creating ideal orthogonal design consisting of 8 profiles. This technique takes into consideration orthogonality, level stability, and marginal overlap [18].

The 8 profiles generated from the orthogonal design facility in SPSS are presented in Table 2.

In order to lessen the respondents' fatigue, the 8 profiles were put together to produce 28 choice sets, which is in the tolerable interval for DCE work, and were randomly blocked into two sets. In the process of the actual survey, the 28 choice sets were given to the individuals to assess and point out the type of company they would desire to purchase a policy from. Table 3 reveals a choice set presented respondents.

2.5. Econometric Specification. Discrete Choice Experiment modeling is embedded in Random Utility Theory (RUT). Nonetheless, the utility can be demonstrated as

$$
U_{c i}=V_{c i}+\epsilon_{c i}
$$

where $U_{c i}$ is the concealed, unobservable utility that individual $i$ associates with choice alternative $c, V_{c i}$ is the determinable variable of the utility, and $\epsilon_{c i}$ is the random variable, making up for uncertainties. The determinable variable $V_{c i}$ of a substitute is a function of the attributes of the substitute itself and the features of the respondent. McFadden [19] puts forward that a utility can be written off as

$$
\begin{aligned}
U_{c i}= & \alpha+\sum_{a-1}^{A} \delta_{a} X_{c a i}+\sum_{n-1}^{N} \gamma_{n} Z_{n i}+\sum_{a-1}^{A} \sum_{m-1}^{M} \beta_{a n} X_{c a i} Z_{n i} \\
& +u_{c i}
\end{aligned}
$$

where company choice $c=$ [Company 1, Company 2] and $i=1 \ldots N$ denotes respondents, $X$ is a vector of $A$ attribute levels, and $Z$ is a vector of $N$ individual characteristics. The parameter $\delta_{a}$ refers to the utility related with the insurance company attribute $a$ and the parameter $\beta_{a n}$ tells how this utility differs by a particular feature of the individual. The variable $u_{c i}$ occurs randomly and characterizes unobservable effects on individual selection. The context assumes that the individual purchases a motor insurance policy from company which generates more utility. The utility gain from choosing Company 2 over Company 1 for respondent $i$ is

$$
\begin{aligned}
U_{2 i}-U_{1 i}= & \sum_{a-1}^{A} \delta_{a}\left(X_{2 a i}-X_{1 a i}\right) \\
& +\sum_{a-1}^{A} \sum_{n-1}^{N} \beta_{a n}\left(X_{2 a i}-X_{1 a i}\right) Z_{n i} \\
& +\left(u_{2 i}-u_{1 i}\right)
\end{aligned}
$$

The randomly occurring component $u_{c i}$ can be theorized to contain of three additive constituents: individual exact component $v_{i}$, company choice component $e_{c}$, and true iid random variable of which the individual specific term cancels out. The company choice specific component may be supposed to be zero, except that the respondents have a constant propensity to be actually more or less probable to choose Company 1 as a substitute for Company 2. The individual chooses Company 2 if

$$
U_{2 i}-U_{1 i}>0
$$

This occurs with the likelihood that

$$
\begin{aligned}
P & {\left[U_{2 i}-U_{1 i}>0\right]=P\left[\sum_{a-1}^{K} \delta_{a}\left(X_{2 a i}-X_{1 a i}\right)\right.} \\
& \left.+\sum_{a-1}^{A} \sum_{n-1}^{N} \beta_{a n}\left(X_{2 a i}-X_{1 a i}\right) Z_{n i}+\left(u_{2 i}-u_{1 i}\right)>0\right] \\
& =P\left[U_{1 i}-U_{2 i}<\sum_{a-1}^{A} \delta_{a}\left(X_{2 a i}-X_{1 a i}\right)\right. \\
& \left.+\sum_{a-1}^{A} \sum_{n-1}^{N} \beta_{a n}\left(X_{2 a i}-X_{1 a i}\right) Z_{n i}\right]
\end{aligned}
$$

Supposing a distribution for $\left(U_{1 i}-U_{2 i}\right)$, for example, a standard normal distribution, the probability above can be written in terms of a cumulative standard normal distribution and modeled consequently with probit:

$$
\begin{gathered}
P\left[U_{2 i}-U_{1 i}>0\right]=P\left[\sum_{a-1}^{A} \delta_{a}\left(X_{2 a i}-X_{1 a i}\right)\right. \\
\left.+\sum_{a-1}^{A} \sum_{n-1}^{N} \delta_{a n}\left(X_{2 a i}-X_{1 a i}\right) Z_{n i}\right]
\end{gathered}
$$

where

$$
F(x)=\Phi(x)=\frac{1}{\sqrt{2 \pi}} \int_{-\infty}^{x} \exp \left(-\frac{1}{2} t^{2}\right) d t
$$


TABLE 2: Orthogonal arrays generated from SPSS.

\begin{tabular}{lcccc}
\hline Choice Set & Premium Cost & Claims Settlement & Customer Service & Proximity \\
\hline 1 & Moderate & Prompt Payment & Satisfactory & Near \\
2 & Maximum & Prompt Payment & Good & Food \\
3 & Minimum & Prompt Payment & Good & Far \\
4 & Moderate & Delayed Payment & Satisfactory & Far \\
5 & Minimum & Delayed Payment & Satisfactory & Near \\
6 & Maximum & Delayed Payment & Good & Near \\
7 & Minimum & Delayed Payment & Satisfactory \\
8
\end{tabular}

TABLE 3: Choice set presented to respondents. Which of these two companies do you want?

\begin{tabular}{lcc}
\hline Attributes & Company 1 & Company 2 \\
\hline Premium Cost & Moderate & Maximum \\
Claims Settlement & Delayed & Delayed \\
Customer Service & Satisfactory & Good \\
Proximity & Near & Near \\
\hline Which company would you choose? & Company 1 [ ] & Company 2 [ ] \\
\hline
\end{tabular}

TABLe 4: Parameter estimates of full model.

\begin{tabular}{lcccc}
\hline Attributes & Coefficients(SE) & Z-Value & P-Value & [95\% Conf. Int.] \\
\hline Moderate Premium & $0.40504(0.04139)$ & 9.787 & 0.0000 & 0.32390 .4864 \\
Maximum Premium & $0.16194(0.04264)$ & 3.798 & 0.0001 & 0.07840 .2455 \\
Prompt Claims & $0.52872(0.03424)$ & 15.442 & 0.0000 & 0.46190 .5959 \\
Satisfactory Customer Service & $-0.05928(0.03432)$ & -1.727 & 0.0841 & -0.126550 .00798 \\
Proximity Near & $0.23173(0.03435)$ & 6.747 & 0.0000 & 0.16440 .2991 \\
Constant & $-0.48887(0.03775)$ & -12.950 & 0.0000 & $-0.5627-0.4152$ \\
Number of observations & 5600 & & & \\
AIC & 7380.1 & & & \\
Likelihood ratio $\chi^{2}$ & 395.14 & & \\
Prob> $\chi^{2}$ & 0.0000 & & & \\
\hline
\end{tabular}

This work provides an estimation for equation (6) with the help of a binary probit model where the levels of Company 1ttributes are taken as metric and dummy variables in the regression analysis. The dependent term (company choice) is assigned 1 if Company 1 is chosen and 0 otherwise. The probit model employed for the research centered on RUT was stated as

$$
\operatorname{Probit}\left(Y=\frac{1}{x}\right)=\operatorname{Probit}\left(U_{\text {Company } 1}>U_{\text {Company } 2}\right)
$$

\section{Model Results and Discussion}

From Table 4, the likelihood ratio chi-square of 395.14 with a corresponding $\mathrm{p}$-value of 0.0000 reveals that the model in general is statistically significant; that is, it fits significantly better than a model with no predictors. For the variable premium cost with subcategories minimum premium, moderate premium, and maximum premium, minimum premium was chosen as the reference subcategory. Also, for the variable claims settlement with subcategories prompt claims payment and delayed claims payment, delayed claims payment was chosen as the reference. Similarly for the variable customer satisfaction and proximity, good customer service and far proximity were chosen as the reference points respectively. From the table, only satisfactory customer service turned out to be statistically insignificant. Insurers with moderate premium levels, prompt claims payment, and nearness to the individual were significant variables that the insured considers in choosing a particular company to insure with. The odds of an individual purchasing a policy from a company with moderate premium as compared to a company with minimum premium (reference point) increase by 0.40504 . However, the odds of an individual purchasing a policy from a company with maximum premium as compared to a company with minimum premium (reference point) increase by 0.16194 . The odds of an individual purchasing a policy from a company with prompt claims payment as compared to companies with delayed claims payment increase by 0.52872 . The odds of an individual purchasing a policy from a company with near proximity as compared to a company with far proximity (reference point) increase by 0.23173 .

The marginal effect results in Table 5 show that insurers with attributes such as moderate premium level, maximum 
TABle 5: Marginal effects of full model.

\begin{tabular}{lccc}
\hline Attributes & $d y / d x(S E)$ & Z-Value & P-Value \\
\hline Moderate Premium & $0.159734(0.015952)$ & 10.0132 & 0.0000 \\
Maximum Premium & $0.064463(0.016904)$ & 3.8135 & 0.0001 \\
Prompt Claims & $0.208496(0.013190)$ & 15.8072 & 0.0000 \\
Satisfactory Customer Service & $-0.023646(0.013685)$ & -1.7278 & 0.0841 \\
Proximity Near & $0.092236(0.013610)$ & 6.7772 & 0.0000 \\
\hline
\end{tabular}

TABLe 6: Parameter estimates of model based on male policyholders.

\begin{tabular}{lcccc}
\hline Attributes & Coefficients(SE) & Z-Value & P-Value & [95\% Conf. Int.] \\
\hline Moderate Premium & $0.36853(0.05231)$ & 7.045 & 0.0000 & 0.26590 .4714 \\
Maximum Premium & $0.11007(0.05402)$ & 2.038 & 0.0416 & 0.00430 .2159 \\
Prompt Claims & $0.63610(0.04332)$ & 14.685 & 0.0000 & 0.55130 .7211 \\
Satisfactory Customer Service & $-0.08871(0.04342)$ & -2.043 & 0.0410 & $-0.1738-0.00362$ \\
Proximity Near & $0.20819(0.04346)$ & 4.791 & 0.0000 & 0.12300 .2934 \\
Constant & $-0.49445(0.04772)$ & -10.362 & 0.000 & $-0.5879-0.4014$ \\
Number of observations & 3528 & & \\
AIC & 4604.4 & & \\
Likelihood ratio $\chi^{2}$ & 302.56 & & \\
Prob $>\chi^{2}$ & 0.0000 & & & \\
\hline
\end{tabular}

TABLE 7: Parameter estimates of model based on female policyholders.

\begin{tabular}{lcccc}
\hline Attributes & Coefficients(SE) & Z-Value & P-Value & [95\% Conf. Int.] \\
\hline Moderate Premium & $0.46760(0.06773)$ & 6.904 & 0.0000 & 0.33490 .6008 \\
Maximum Premium & $0.24961(0.06977)$ & 3.578 & 0.0003 & 0.11300 .3864 \\
Prompt Claims & $0.34388(0.05603)$ & 6.138 & 0.0000 & 0.23410 .4538 \\
Satisfactory Customer Service & $-0.01634(0.05615)$ & -0.291 & 0.7710 & -0.12640 .0937 \\
Proximity Near & $0.27341(0.05619)$ & 4.865 & 0.0000 & 0.0000 \\
Constant & $-0.47626(0.06170)$ & -7.719 & & $-0.5970-0.3559$ \\
Number of observations & 2072 & & & \\
AIC & 2770.2 & & \\
Likelihood ratio $\chi^{2}$ & 114.24 & & & \\
Prob $>\chi^{2}$ & 0.0000 & & & \\
\hline
\end{tabular}

premium level, prompt claims payment, and proximity near significantly increase the utility of the change in the likelihood of purchasing a motor insurance policies by 0.159734 , $0.064463,0.208496$, and 0.092236 , respectively, as compared to an insurer with a minimum premium level, delayed claims payment, and far proximity. It can be observed that even though insurers with maximum premium levels are also significant they do not really affect the change in the probability of choosing between alternative motor insurance policies. Also, satisfactory customer service as an attribute of an insurer decreases the difference in the likelihood of choosing between alternative motor insurance policies as compared to good customer service.

\section{Subgroup Analysis according to Gender}

The outputs in Tables 6 and 7 are estimated models restricted by gender. The data was subdivided according to males and females to see if there will be any difference in their outcome compared to the full model. The attributes however actually had similar effects compared to the ones estimated in the unrestricted model. There was however one notable change which is the fact that satisfactory customer service was significant in the model restricted to males only. The coefficient implies that satisfactory customer service among males will result in disutility of preference for an insurer as compared to a company with good customer service.

\section{Conclusion}

The study sought out to assess the effects of various insurance company attributes on drivers and vehicle owners in choosing a desired motor insurance policy. The study revealed that the levels of opportunities for further studies (premium level being moderate and maximum), claims payment (prompt), and proximity of the insurer (near) play essential roles in the 
choice decisions of drivers and vehicle owners with regards to purchasing a motor insurance policy, which were further supported by the marginal effects. The resulting effects of some attributes from findings from the study showed that, in choosing between alternative motor insurance policies, respondents consideration sets in order of importance were prompt claims payment, moderate premium level, and near proximity. The most important attribute that influences the choice between alternative insurance policies is prompt claims payment. Generally, customer satisfaction would be traded off for other attributes (prompt claims payment, moderate premium level, and near proximity).

The outcome of this study can be used by underwriters and policymakers in the insurance industry to put forward measures for the improvement of their services in gravitating more customers to achieve one of the main concepts of insurance which is risk pooling.

\section{Data Availability}

The data was collected using questionnaires.

\section{Conflicts of Interest}

The authors declare that they have no conflicts of interest.

\section{References}

[1] Anderson \& Brown (2005). "Risk and insurance". Education and examination committee of the society of actuaries. https://cdn-files.soa.org/sslerror.

[2] MSS (Publishing \& Media) Consultants, The Financial Products, Investment \& Insurance Buyers' Guide for IFAs, Brokers \& Financial Managers, 2010, http://www.mss-media-consultants .co.uk/Fin-Products-Guide.pdf.

[3] L. Brainard, What Is The Role of Insurance in Economic Development?vol. 03, Zurich, 2008, https://www.zurich.com/what_is_ the_role_of_econo.

[4] Insurance Australia Group (IAG). (2011). General insurance, https://www.nzi.co.th/images/IAG\%20Insurance\%20Basics .pdf.

[5] Onafalujo and A. Kunle, "Effects of Risk perception on the demand for insurance: implications on Nigerian road users," Journal of Emerging Trends in Economics and Management Sciences (JETEMS), vol. 2, Lagos State University, Ojo, Lagos, no. 4, pp. 285-290, 2011.

[6] L. J. Blincoe, T. R. Miller, E. Zaloshnja, and B. A. Lawrence, The Economic and Societal Impact of Motor Vehicle Crashes, 2010 (Revised), National Highway Traffic Safety Administration, Washington D.C., 2015, https://crashstats.nhtsa.dot.gov/Api/ Public/ViewPublication/812013.

[7] I. Kwiecien and E. Poprawska, "Motor third party liability insurance: Polish market in connections to the European trends," International Journal of Economics and Finance Studies, vol. 3, 2011.

[8] P. Rossi and J. R. Black, Entrepreneurship and Innovation in Automobile Insurance, Routledge, New York, NY, 2001.

[9] J. D. Cummins and S. Tennyson, "Moral hazard in insurance claiming: Evidence from automobile insurance," Journal of Risk and Uncertainty, vol. 12, no. 1, pp. 29-50, 1996.
[10] M. Beenstock, G. Dickinson, and S. Khajuria, "The relationship between property-liability insurance premiums and income: An international analysis," Journal of Risk and Insurance, vol. 55, no. 2, p. 259, 1988.

[11] V. E. Showers and J. A. Shotick, "The effects of household characteristics on demand for insurance: A tobit analysis," Journal of Risk and Insurance, vol. 61, no. 3, p. 492, 1994.

[12] M. J. Browne and R. E. Hoyt, "The demand for flood insurance: empirical evidence," Journal of Risk and Uncertainty, vol. 20, no. 3, pp. 291-306, 2000.

[13] D. N. Gujarati, Basic Econometrics, McGraw-Hill Companies, 4th edition, 1995.

[14] N. L. Damaraju, J. B. Barney, and A. K. Makhija, "Real options in divest-ment alternatives," Strategic Management Journal, vol. 36, pp. 728-744, 2015.

[15] D. A. Hensher, J. M. Rose, and W. H. Greene, Applied Choice Analysis, A Primer, Cambridge University Press, Cambridge, 2005.

[16] W. Adamowicz, J. Louviere, and J. Swait, Introduction to Attribute-Based Stated Choice Methods, Resource Valuation Branch Damage Assessment Center, NOAA, U.S Department of Commerce, Washinton, 1998.

[17] J. J. Louviere, D. A. Hensher, and J. D. Swait, Stated Choice Methods, Analysis and Applications, Cambridge University Press, 2000.

[18] W. F. Kuhfeld, "Construction of efficient designs for discrete choice experiment," Journal of Market Research, vol. 31, pp. 375$383,2010$.

[19] D. McFadden, "Conditional logit analysis of qualitative choice behaviour," In Frontiers in Econometrics, pp. 105-142, 1974. 


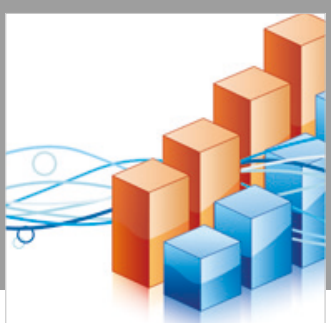

Advances in

Operations Research

\section{-n-m}
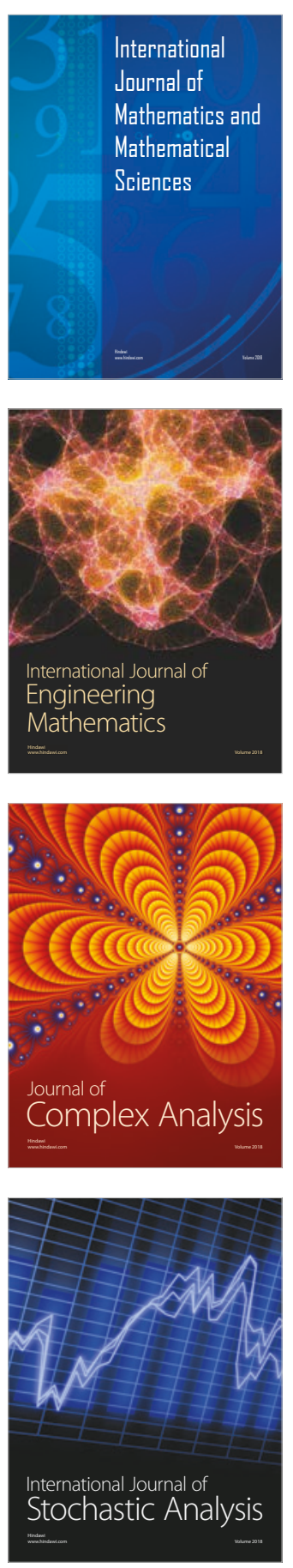
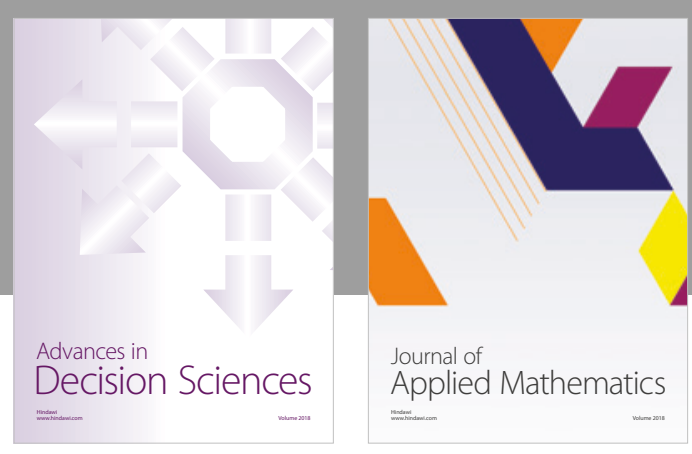

Journal of

Applied Mathematics
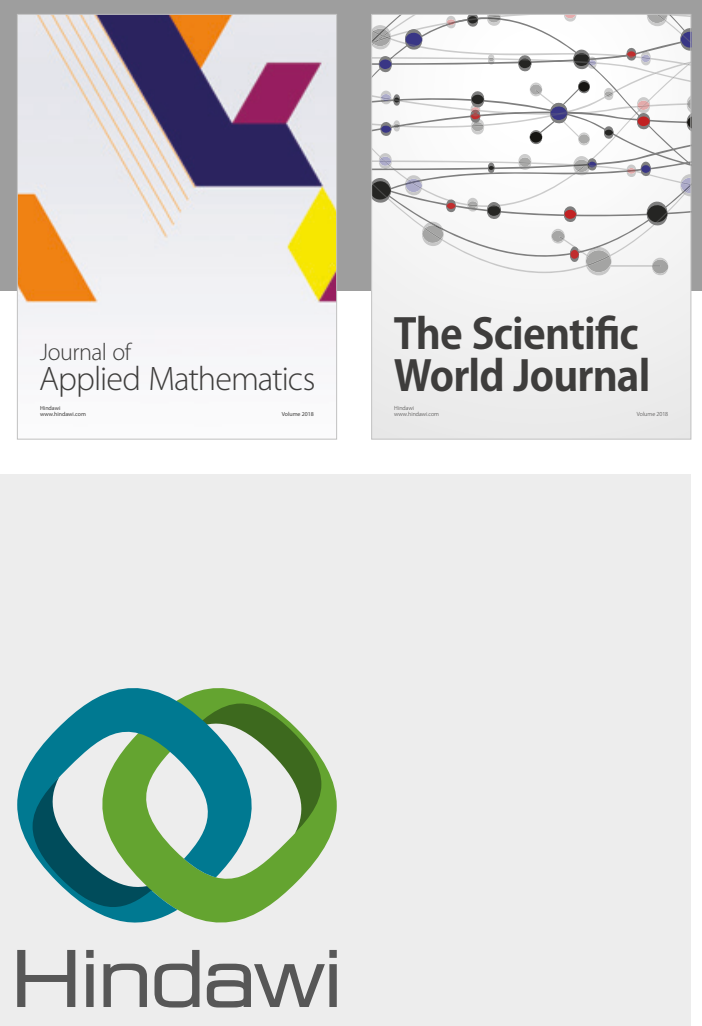

Submit your manuscripts at

www.hindawi.com

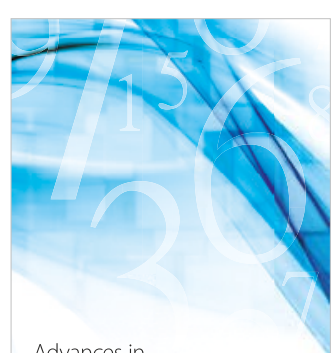

Advances in
Numerical Analysis
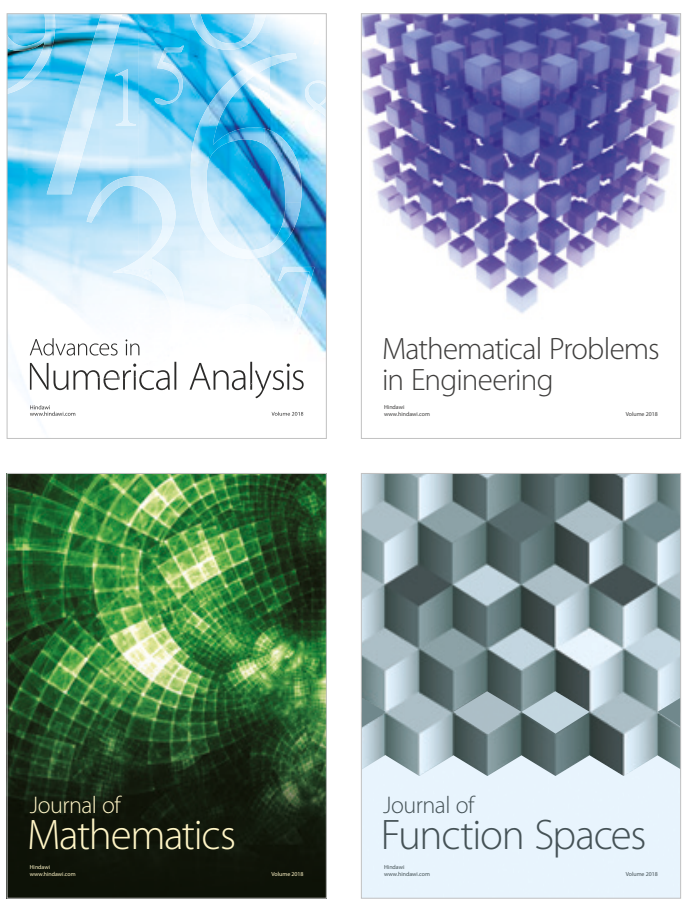

Mathematical Problems in Engineering

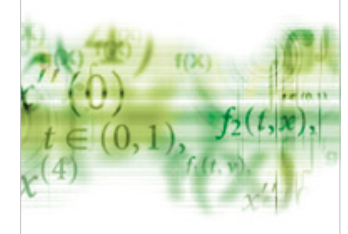

International Journal of

Differential Equations

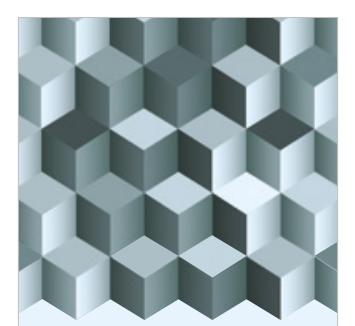

Journal of

Function Spaces

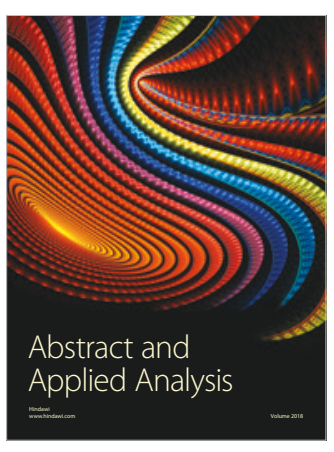

The Scientific

World Journal

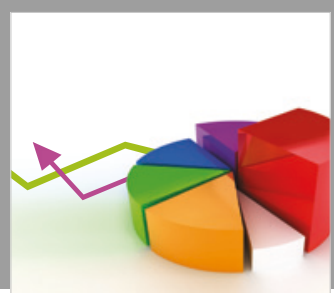

Journal of

Probability and Statistics
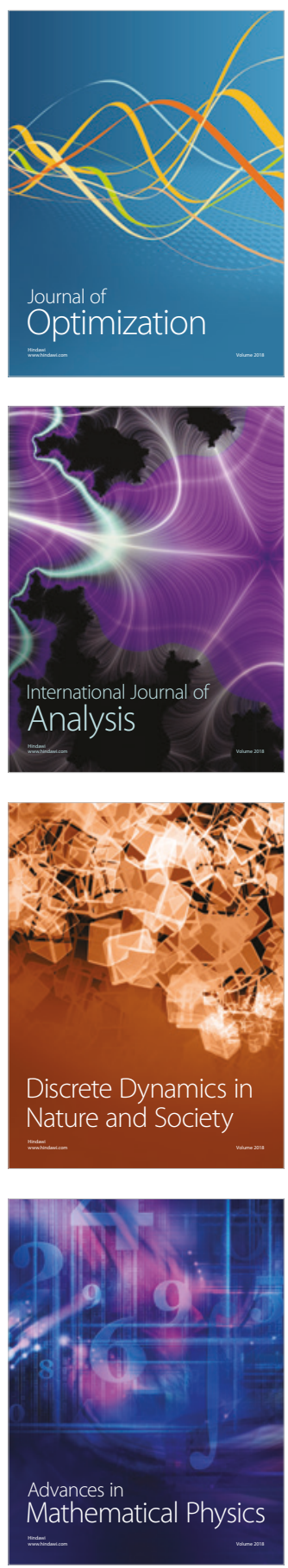